\title{
L-Arginine attenuates xanthine oxidase and myeloperoxidase activities in hearts of rats during exhaustive exercise
}

\author{
Wan-Teng Lin ${ }^{1,4}$, Suh-Ching Yang ${ }^{2}$, Shiow-Chwen Tsai ${ }^{3}$, Chi-Chang Huang ${ }^{2}$ and Ning-Yuean Lee ${ }^{1 *}$ \\ ${ }^{1}$ Department of Nutrition and Food Sciences, Fu-Jen Catholic University, Taipei, Taiwan, Republic of China \\ ${ }^{2}$ School of Nutrition and Health Sciences, Taipei Medical University, Taipei, Taiwan, Republic of China \\ ${ }^{3}$ Central Laboratory, Shin Kong Wu Ho-Su Memorial Hospital, Taipei, Taiwan, Republic of China \\ ${ }^{4}$ De Lin Institute of Technology, Taipei, Taiwan, Republic of China
}

(Received 21 January 2005 - Revised 23 June 2005 - Accepted 12 August 2005)

\begin{abstract}
The present study was to investigate the effects of L-arginine (L-Arg) supplementation on cardiac oxidative stress and the inflammatory response in rats following acute exhaustive exercise on a treadmill. Rats were randomly divided into four groups: sedentary control (SC); SC with L-Arg treatment $(\mathrm{SC}+\mathrm{Arg})$; exhaustive exercise (E); exhaustive exercise with L-Arg treatment $(\mathrm{E}+\mathrm{Arg})$. Rats in groups $\mathrm{SC}+\mathrm{Arg}$ and $\mathrm{E}+\mathrm{Arg}$ received a $2 \% \mathrm{~L}$-Arg diet. Rats in groups $\mathrm{E}$ and $\mathrm{E}+$ Arg performed an exhaustive running test on a treadmill at a final speed of $30 \mathrm{~m} / \mathrm{min}, 10 \%$ grade, at approximately $70-75 \% \mathrm{~V}_{\mathrm{O} 2 \max }$. The results showed a significant increase in cardiac xanthine oxidase (XO) and myeloperoxidase activities and membrane lipid peroxidation endproduct (malondialdehyde; MDA) levels of exercised rats compared with SC rats. The increased cardiac XO activity and MDA levels in exercised rats were significantly decreased in exercised rats supplemented with L-Arg. Myocardial GSSG content increased whereas the GSH:GSSG ratio was depressed in exercised rats compared with SC rats. Cardiac GSSG levels significantly decreased, whereas total glutathione, GSH and the GSH:GSSG ratio increased in exercised rats supplemented with L-Arg compared with exercised rats. The activities of creatinine kinase (CK) and lactate dehydrogenase (LDH), and lactate, uric acid, and nitrite and nitrate levels in the plasma significantly increased in exercised rats compared with SC rats. The activities of plasma CK and LDH were significantly decreased in L-Arg-supplemented plus exercised rats compared with exercised rats. These findings suggest that L-Arg supplementation reduces the oxidative damage and inflammatory response on the myocardium caused by exhaustive exercise in rats.
\end{abstract}

L-Arginine: Xanthine oxidase: Myeloperoxidase: Oxidative stress: Exhaustive exercise

The heart tissues are mostly composed of muscles that contain plenty of mitochondria, which need more $\mathrm{O}_{2}$ compared with other organs. Basically, the heart needs lots of $\mathrm{O}_{2}$ to work well. Nowadays, $\mathrm{O}_{2}$ is sometimes apt to be dealt with as a negative factor in oxidative stress instead of as an indispensable factor for life activity. Although increased $\mathrm{O}_{2}$ flux through the mitochondrial electron transport chain is considered the main source of reactive oxygen species (ROS), other pathways of ROS generation, such as xanthine oxidase (XO) and polymorphoneutrophils, may also be activated during or after strenuous exercise ( $\mathrm{Ji}, 1999)$.

In previous studies, exhaustive physical exercise has been known to induce free radicals in vivo and lead to oxidative damage in several tissues such as muscle, liver, lung, and heart (Kumar et al. 1992; Frankiewicz-Jozko et al. 1996; Ashton et al. 1998; Radak et al. 1998). During exhaustive exercise, XO activity was significantly increased in the circulation and tissues (Radak et al. 1995; Hellsten et al. 1997; Vina et al. 2000). XO, a metalloflavoprotein, has a major role for oxygen-derived free radicals in post-ischaemic tissue injury (McCord, 1985). Vina et al. (2000) further demonstrated that $\mathrm{XO}$ is responsible for free radical production and tissue damage during exhaustive exercise. Recently, it was proposed that $\mathrm{XO}$-derived oxidants are chemotactic to neutrophils (Judge \& Dodd, 2004). In human and animal studies, neutrophil infiltration in tissues is associated with strenuous exercise-induced tissue damage (Fielding et al. 1993; Belcastro et al. 1996). Neutrophils are capable of further generation of free radicals via NADPH oxidase and producing $\mathrm{HOCl}$ from $\mathrm{H}_{2} \mathrm{O}_{2}$ via myeloperioxidase (MPO), a marker for neutrophil infiltration in tissues, in the initiation of exerciseinduced muscle damage (Tiidus, 1998). These studies indicate that both XO and MPO are the two main sources of extracellular free radicals during strenuous exercise. These two enzymes are also responsible for exhaustive exercise-induced oxidative stress in several tissues including muscle, liver, and heart.

$\mathrm{L}$-Arginine ( $\mathrm{L}-\mathrm{Arg}$ ) is used in current basic and clinical research for its important therapeutic qualities. Most

Abbreviations: AST, aspartate aminotransferase; CAT, catalase; CK, creatinine kinase; E, exhuastive exercise; GPX, glutathione peroxidase; GR, glutathione reductase; L-Arg, L-arginine; LDH, lactate dehydrogenase; MDA, malondialdehyde; MPO, myeloperoxidase; NOx, nitrite and nitrate; ROS, reactive oxygen species; SC, sedentary control; SOD, superoxide dismutase; UA, uric acid; XO, xanthine oxidase.

* Corresponding author: Dr Ning-Yuean Lee, fax +88622904 3234, email als2046@mails.fju.edu.tw 
pharmacological actions of L-Arg are attributed to NO, which is able to act on a wide range of tissues and is a multipurpose messenger molecule implicated in a wide variety of biological processes (Wu \& Morris, 1998). For example, in patients with CVD, intravenous and oral L-Arg administration has been shown to support endothelial function by enhancing vasodilatation and reducing monocyte adhesion (Wang et al. 1994). Increasing NO bioactivity through L-Arg supplementation has been shown to reduce blood lactate and $\mathrm{NH}_{3}$ after maximal or submaximal exercise (Schaefer et al. 2002). Recent findings suggest that L-Arg supplementation could significantly enhance the exercised-induced increases of NO production and changes of $\mathrm{Fe}$ metabolism (Xiao et al. 2003). Several studies have also demonstrated that L-Arg has a protective role against ROS attack. This was possible due to its direct chemical interaction with superoxide anions $\left(\mathrm{O}_{2}{ }^{-}\right)$in vitro (Wascher et al. 1997; Lass et al. 2002). However, so far as we know, there is no study investigating the effect of L-Arg supplementation on cardiac XO activity, the inflammatory response and antioxidant defence systems during exhaustive exercise. We therefore studied whether dietary L-Arg may protect heart tissue and have beneficial effects on ameliorating exercise-induced oxidative stress and inflammation in the myocardium of rats.

\section{Materials and methods}

Thirty-two male Sprague-Dawley rats weighing 280-300 g (8 weeks old) were purchased from the National Laboratory Animal Breeding and Research Center (Taipei, Taiwan). All rats were given free access to water and standard pelleted rat food (no. 5001; PMI Nutrition International, Brentwood, MO, USA) and individually housed in a room maintained at $23 \pm 2^{\circ} \mathrm{C}$ with a $12 \mathrm{~h}$ light-dark cycle. In order to adapt to the experimental standard diet, rats were fed an AIN-93 diet in the second week. Afterward, rats were randomly divided into four groups: a sedentary control group with AIN-93 diet (SC; $n$ 8); sedentary control with AIN-93 containing $2 \%$ L-Arg diet (SC $+\mathrm{Arg} ; n$ 8); exhaustive exercise with AIN93 diet $(\mathrm{E} ; n$ 8); exhaustive exercise with AIN-93 containing $2 \%$ L-Arg diet (E + Arg; $n$ 8). Rats were fed diets for $30 \mathrm{~d}$ beginning in the third week. Both diets were identical in energy content (Table 1) (Reeves et al. 1993; Lewis \& Langkamp-Henken, 2000). The experiment was approved by the Fu-Jen Catholic University Animal Care and Usage Committee and followed the guidelines established by the National Laboratory Animal Breeding and Research Center in Taiwan. It is well known that exercise performance is limited by increase of body temperature during exercise. In order to eliminate this complicating factor, all running tests were conducted in an environmental chamber at $10-12^{\circ} \mathrm{C}$ to reduce the undue rise in body temperature due to sustained exercise.

Rats in groups E and E + Arg were introduced to treadmill running with $15-20 \mathrm{~min}$ exercise bouts at $15-30 \mathrm{~m} / \mathrm{min}$ for $6 \mathrm{~d}$ to accustom them to running by a modification of the method of Ji et al. (1991). The treadmill was equipped with an electric shocking grid on the rear barrier to provide the animal with exercise motivation (T510E treadmill device; DR instrument, Taipei, Taiwan). On the day of the exercise test, they were required to run to exhaustion on a six-lane inclined $\left(10^{\circ}\right)$ treadmill at a final speed of $30 \mathrm{~m} / \mathrm{min}$, which was approximately $70-75 \%$ of $\mathrm{V}_{\mathrm{O} 2 \max }$ (Brooks \& White, 1978). The measurement of maximal $\mathrm{O}_{2}$ consumption $\left(100 \% \mathrm{~V}_{\mathrm{O} 2 \max }\right)$ was considered valid only if the animal ran until it could no longer maintain pace with the treadmill (Somani et al. 1995). Therefore, exhaustion was determined as the rat being unable to upright itself when placed on its back (Ji \& Mitchell, 1994; de Oliveira et al. 2003). To eliminate diurnal effects, the experiments were performed at the same time (09.00 hours to 12.00 hours).

All animals were anaesthetised with ethyl ether and killed immediately after exhaustive exercise. After anaesthesia, body temperature was measured by use of a rectal thermometer. Then, the heparinised blood sample was collected from the abdominal aorta and the heart tissue was carefully removed, rinsed in ice-cold normal saline, blotted dry and stored at $-80^{\circ} \mathrm{C}$ for further analysis.

Heart tissues $(100 \mathrm{~g} / \mathrm{l})$ were homogenised in ice-cold buffer (sucrose $(0.25 \mathrm{~mol} / \mathrm{l})$, tri(hydroxymethyl)-aminomethane- $\mathrm{HCl}$ $(10 \mathrm{mmol} / \mathrm{l})$, and phenylmethylsulfonyl fluoride $(0.25 \mathrm{mmol} / \mathrm{l})$; $\mathrm{pH}$ 7.4) using a Polytron homogeniser (Kinematica $\mathrm{GmbH}$, Lucerne, Switzerland) with a Teflon pestle and glass tube (Glas-Col, Terre Haute, IN, USA). The homogenates were centrifuged at $10000 \mathrm{~g}$ for $20 \mathrm{~min}$ at $4^{\circ} \mathrm{C}$. The supernatant fractions

Table 1. Composition of the diets based on the AIN-93 diet (Reeves et al. 1993)*

\begin{tabular}{lcccr}
\hline Ingredient $(\mathrm{g} / \mathrm{kg})$ & Group SC & Group SC + Arg & Group E & Group E + Arg \\
\hline Casein & 200 & 200 & 200 & 200 \\
L-Cystine & 3 & 3 & 3 & 3 \\
L-Arginine & 0 & 16 & 0 & 16 \\
Maize starch & 397.5 & 381 & 397.5 & 381 \\
Maltodextrin & 132 & 132 & 132 & 132 \\
Sucrose & 100 & 100 & 100 & 100 \\
Soyabean oil & 70 & 70 & 70 & 70 \\
Cellulose & 50 & 30 & 50 & 50 \\
AIN-93 mineral mix & 35 & 10 & 35 & 35 \\
AlN-93 vitamin mix & 10 & 2.5 & 10 & 10 \\
Choline bitartrate & 2.5 & 0.014 & 2.5 & 2.5 \\
tert-Butylhydroquinone & 0.014 & & 0.014 & 0.014 \\
\hline
\end{tabular}

SC, sedentary control; Arg, L-arginine; E, exhaustive exercise.

* The components for the diets were purchased from ICN Biochemicals, Inc. (Costa Mesa, CA, USA), with the exception of Larginine, sucrose and soyabean oil, which were obtained from Sigma-Aldrich-Fluka (St Louis, MO, USA). For details of diets and procedures, see p. 68. 
were transferred to a new Eppendorff tube and used for determination of XO activity, antioxidant enzyme activities and protein levels. The pellets were washed twice in an ice-cold buffer (phosphate buffer; $20 \mathrm{mmol} / \mathrm{l} ; \mathrm{pH} \mathrm{6.0)}$ ) and sonicated in MPO homogenisation buffer containing $0.5 \%$ hexadecyltrimethylammonium bromide, EDTA $(10 \mathrm{mmol} / \mathrm{l})$ and phosphate buffer $(50 \mathrm{mmol} / \mathrm{l})(\mathrm{pH} 6.0)$ at $25^{\circ} \mathrm{C}$ for $1 \mathrm{~min}$ with an ultrasonic processor (Vibra Cell model VCX-500; Sonics and Materials Inc., Danbury, CT, USA). The homogenates were then centrifuged at $17000 \mathrm{~g}$ at $4^{\circ} \mathrm{C}$ for $15 \mathrm{~min}$. Supernatant fractions were aspirated into new tubes and stored on ice until the assay was performed. In addition, all samples were diluted in deionised water for analysis, if necessary. All chemicals used in the present study were purchased from Sigma-Aldrich-Fluka (St Louis, MO, USA) unless stated otherwise.

\section{Plasma parameters}

Blood samples were centrifuged at $1400 \mathrm{~g}$ at $4^{\circ} \mathrm{C}$ for $10 \mathrm{~min}$. The supernatant fractions (plasma) were used for the determination of creatinine kinase (CK), aspartate aminotransferase (AST), lactate dehydrogenase (LDH) and uric acid (UA) with an automatic analyser (Hitachi 7170; Hitachi, Tokyo, Japan). In addition, nitrate and nitrite (NOx) levels in plasma were quantified by using the Griess reagent to measure nitrite ion concentration (Green et al. 1982). NOx concentrations in plasma were measured spectrophotometrically at $550 \mathrm{~nm}$ according to a previous study (Schmidt et al. 1992).

\section{Assay of xanthine oxidase activity in the heart tissue}

XO activity of heart tissue was determined by the method of Westerfeld et al. (1959). A diluted sample was added to xanthine $(0.1 \mathrm{mmol} / \mathrm{l})$ (dissolved in sodium phosphate buffer, $50 \mathrm{mmol} / \mathrm{l} ; \mathrm{pH} \mathrm{7.5)}$. XO activity was measured at $25^{\circ} \mathrm{C}$ on a Hitachi U-2000 spectrophotometer at $290 \mathrm{~nm}$ for $3 \mathrm{~min}$. One unit of XO activity was defined as $1 \mu \mathrm{mol}$ urate formation/ $\min$ at $25^{\circ} \mathrm{C}$. $\mathrm{XO}$ activity was expressed as $\mathrm{U} / \mathrm{g}$ protein for specific activity.

\section{Assay of myeloperoxidase activity in the heart tissue}

MPO activity of heart tissue was determined as a marker enzyme for measuring neutrophils accumulating in tissue samples, because it is closely correlated with the number of neutrophils present in the tissue (Mullane et al. 1985). MPO activity was determined by the method of Schierwagen et al. (1990). A portion of diluted sample $(50 \mu \mathrm{l})$ was added to $1 \mathrm{ml}$ mixed substrate containing $\mathrm{H}_{2} \mathrm{O}_{2}(3 \mathrm{mmol} / \mathrm{l})$ dissolved in 3,3',3,5'-tetramethylbenzidine (R\&D Systems Inc., Minneapolis, MN, USA). MPO activity was measured at $37^{\circ} \mathrm{C}$ on a Hitachi U-2000 spectrophotometer at $655 \mathrm{~nm}$ for $3 \mathrm{~min}$. One unit of MPO activity was defined arbitrarily as the amount of enzyme necessary to catalyse an increase in absorbance of 1.0 at $655 \mathrm{~nm} / \mathrm{min}$ at $37^{\circ} \mathrm{C}$. MPO activity was expressed as $\mathrm{U} / \mathrm{mg}$ protein for specific activity.

\section{Lipid peroxidation in the heart tissue}

The malondialdehyde (MDA) concentration of the heart tissue homogenate was assessed colorimetrically at $586 \mathrm{~nm}$ using a commercial kit (Calbiochem 437634; Calbiochem-Novabiochem, La Jolla, CA, USA).

\section{Assay of superoxide dismutase activity in the heart tissue}

Superoxide dismutase (SOD) activity of heart tissue was measured with a commercial kit (SD 125; Randox Laboratories, Antrim, UK). A portion of diluted standard or sample $(50 \mu \mathrm{l})$ was added to $1.7 \mathrm{ml}$ mixed substrate (xanthine (50 $\mu \mathrm{mol} / \mathrm{l})$ and 2-(4-iodophenyl)-3-(4-nitrophenol)-5-phenyltetrazolium chloride $(25 \mu \mathrm{mol} / \mathrm{l}))$. XO $(250 \mu \mathrm{l} ; 80 \mathrm{U} / \mathrm{l})$ was added to the mixture and SOD activity was measured by the degree of inhibition of this reaction at $37^{\circ} \mathrm{C}$ on a Hitachi U-2000 spectrophotometer at $505 \mathrm{~nm}$ for $3 \mathrm{~min}$. Activity was expressed as U/mg protein for specific activity.

\section{Assay of catalase activity in the heart tissue}

Catalase (CAT) activity of heart tissue was determined at $25^{\circ} \mathrm{C}$ with a Hitachi U-2000 spectrophotometer UV-VIS spectrophotometer by the method of Beers \& Sizer (1952). A diluted sample was added to $\mathrm{H}_{2} \mathrm{O}_{2}(59 \mathrm{mmol} / \mathrm{l})$ (dissolved in potassium phosphate buffer; $50 \mathrm{mmol} / \mathrm{l} ; \mathrm{pH} 7 \cdot 0$ ) and CAT activity was measured at $240 \mathrm{~nm}$ for $3 \mathrm{~min}$. One unit of CAT activity was defined as $1 \mathrm{mmol} \mathrm{H}_{2} \mathrm{O}_{2}$ degraded/min. Activity was expressed as $\mathrm{U} / \mathrm{mg}$ protein for specific activity.

\section{Assay of glutathione peroxidase activity in the heart tissue}

Glutathione peroxidase (GPX) activity of heart tissue was determined with a commercial kit (RS 504; Randox Laboratories, Antrim, UK). A portion of diluted sample $(20 \mu \mathrm{l})$ was added to $1 \mathrm{ml}$ mixed substrate (glutathione $(4 \mathrm{mmol} / \mathrm{l})$, glutathione reductase $(\mathrm{GR} ; 0.5 \mathrm{U} / \mathrm{l})$ and NADPH $(0.34 \mathrm{mmol} / \mathrm{l})$ dissolved in phosphate buffer $(50 \mathrm{mmol} / \mathrm{l})$; $\mathrm{pH} 7 \cdot 2$; EDTA, $4.3 \mathrm{mmol} / \mathrm{l})$. Cumene hydroperoxide $(40 \mu \mathrm{l}$; diluted in deionised water) was added to the mixture and GPX activity was measured at $37^{\circ} \mathrm{C}$ on a Hitachi U-2000 spectrophotometer at $340 \mathrm{~nm}$ for $3 \mathrm{~min}$. One unit of GPX activity was defined as the amount of enzyme that catalysed the reduction of 1 $\mu \mathrm{mol} \mathrm{NADPH} / \mathrm{min}$. Activity was expressed as $\mathrm{U} / \mathrm{mg}$ protein for specific activity.

\section{Assay of glutathione reductase activity in the heart tissue}

GR activity of heart tissue was measured with a commercial kit (Calbiochem 359962; Calbiochem-Novabiochem). A portion of diluted sample $(200 \mu \mathrm{l})$ was added to $400 \mu \mathrm{l} \mathrm{GSSG}$ buffer $(2.4 \mathrm{mmol} / \mathrm{l}$; dissolved in potassium phosphate buffer (125 mmol/l); pH 7.5; EDTA, 2.5 mmol/l). NADPH (400 $\mu \mathrm{l}$; $0.55 \mathrm{mmol} / \mathrm{l}$; dissolved in deionised water) was added to the mixture and GR activity was measured at $340 \mathrm{~nm}$ for $5 \mathrm{~min}$ on a Hitachi U-2000 spectrophotometer. One unit of GR activity was equal to $1 \mu \mathrm{mol}$ NADPH oxidised/min. Activity was expressed as $\mathrm{mU} / \mathrm{g}$ protein for specific activity. 
Assay of total and oxidised glutathione in the heart tissue

Total glutathione was determined using a modification of the method of Tietze (1969). Total glutathione was assayed by the addition of $190 \mu \mathrm{l}$ freshly prepared assay buffer (NADPH (100 $\mu \mathrm{mol} / \mathrm{l}), 5,5^{\prime}$-dithiobis-(2-nitrobenzoic acid) $(5 \mathrm{mmol} / \mathrm{l})$, GR (1 unit/ml), EDTA $(1 \mathrm{mmol} / \mathrm{l})$ and phosphate buffer ( $50 \mathrm{mmol} / \mathrm{l}) ; \mathrm{pH} 7.2)$ to $10 \mu \mathrm{l}$ diluted sample. The change in absorbance was measured after $3 \mathrm{~min}$ at $405 \mathrm{~nm}$ using a microplate reader (Labsystem Multiskan RC, Helsinki, Finland) and compared with a standard curve, from 0 to $100 \mu \mathrm{mol} / \mathrm{l}$.

GSSG was determined by the method of Griffith (1980). Diluted samples or standards $(70 \mu \mathrm{l})$ were derivatised with 1-methyl-2-vinylpyridinium trifluoromethane sulfonate to remove GSH by adding $4 \mu 1$ 1-methyl-2-vinylpyridinium trifluoromethane sulfonate and $3 \cdot 2 \mu$ l triethanolamine. Samples were left at room temperature for $1 \mathrm{~h}$ to allow the reaction to occur. The GSSG that remained was then assayed in the same manner as for total glutathione.

\section{Total protein concentrations in samples}

Total protein concentrations of samples were spectrophotometrically estimated according to the method of Lowry et al. (1951) using a Bio-Rad DC protein assay kit (catalogue no. 500-0116; Bio-Rad Laboratories, Hercules, CA, USA).

\section{Statistical analysis}

Values are expressed as means with their standard errors. To evaluate differences among the groups studied, two-way ANOVA with Fisher's post hoc test was used. SAS software (version 8.2; SAS Institute Inc., Cary, NC, USA) was used to analyse all data. Differences were considered statistically significant when $P<0 \cdot 05$.

\section{Results}

\section{Body weight and endurance time}

At the end of $30 \mathrm{~d}$, body weight in the groups SC, SC + Arg, $\mathrm{E}$ and $\mathrm{E}+\mathrm{Arg}$ were 446 (SEM 7), 446 (SEM 10), 447 (SEM 6) and 451 (SEM 8) g, respectively. There were no significant differences in body weight among the four groups. The mean endurance time of treadmill running to exhaustion was 81 (SEM 4) min for group E and 87 (SEM 5) min for group $\mathrm{E}+$ Arg, which was not significantly different between the two groups.

\section{Xanthine oxidase activity in the heart tissue}

As shown in Fig. 1, XO activity of heart in group E was significantly increased by $87 \%$ compared with that in group SC. However, $\mathrm{XO}$ activity was significantly decreased by $44 \%$ in group $\mathrm{E}+$ Arg compared with group $\mathrm{E}(P<0 \cdot 05)$.

\section{Myeloperoxidase activity in the heart tissue}

The degree of neutrophil infiltration in the myocardium is shown in Fig. 2. In comparison with group SC, MPO activity of heart in group $\mathrm{E}$ was significantly increased by $18 \%$ $(P<0.05)$.

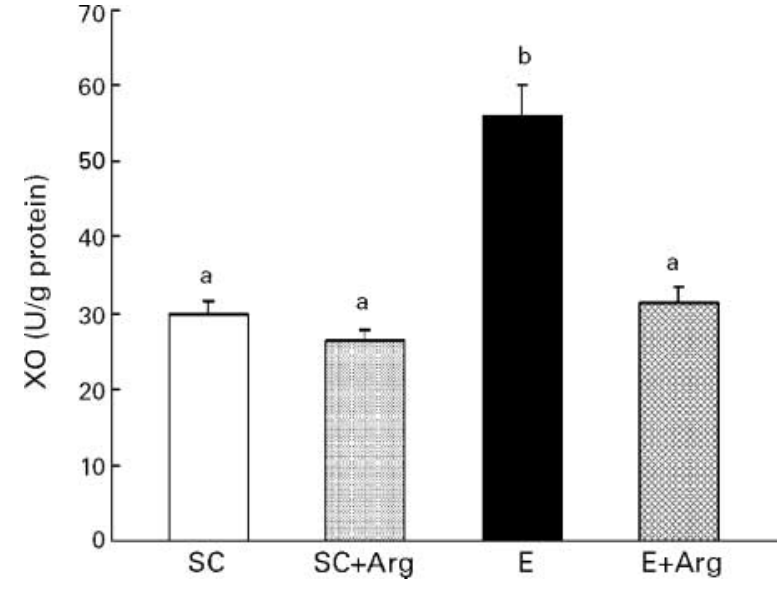

Fig. 1. Effect of L-arginine (Arg) supplementation on xanthine oxidase (XO) activity of heart tissue after exhaustive exercise (E). SC, sedentary control. Values are means for eight rats, with their standard errors represented by vertical bars. Statistical differences among the groups were determined by two-way ANOVA. ${ }^{\mathrm{a}, \mathrm{b}}$ Mean values with unlike letters were significantly different by Fisher's least significant difference test $(P<0.05)$. For details of diets and procedures, see p. 68.

\section{Lipid peroxidation in the heart tissue}

MDA, a quantitative marker of lipid peroxidation, was measured in the heart tissue as shown in Fig. $3(P<0.05)$. The content of MDA in group $\mathrm{E}$ was significantly elevated by $44 \%$ compared with group SC. When compared with group E, the elevation of MDA content was significantly decreased in group $\mathrm{E}+\operatorname{Arg}(P<0 \cdot 05)$.

Plasma creatinine kinase, aspartate aminotransferase, lactate dehydrogenase, uric acid, and nitrite and nitrate levels

Plasma CK, AST, LDH, UA, and NOx levels in group E were all significantly elevated by $453,81,363,268$ and $93 \%$, respectively, compared with those in group SC $(P<0.05)$ (Table 2). In contrast, the CK and LDH activities of plasma were significantly lowered by 46 and $33 \%$, respectively, in

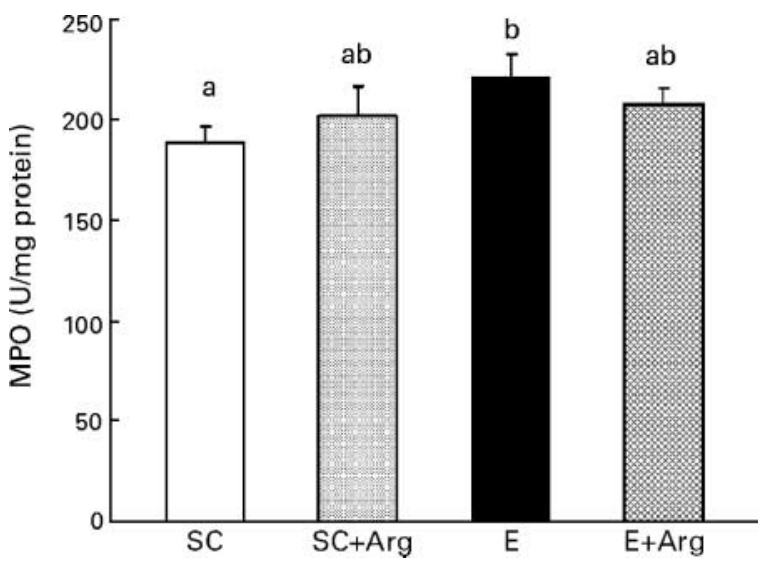

Fig. 2. Effect of L-arginine (Arg) supplementation on myeloperoxidase (MPO) activity of heart tissue after exhaustive exercise (E). SC, sedentary control. Values are means for eight rats, with their standard errors represented by vertical bars. Statistical differences among the groups were determined by two-way ANOVA. ${ }^{a, b}$ Mean values with unlike letters were significantly different by Fisher's least significant difference test $(P<0.05)$. For details of diets and procedures, see p. 68 . 


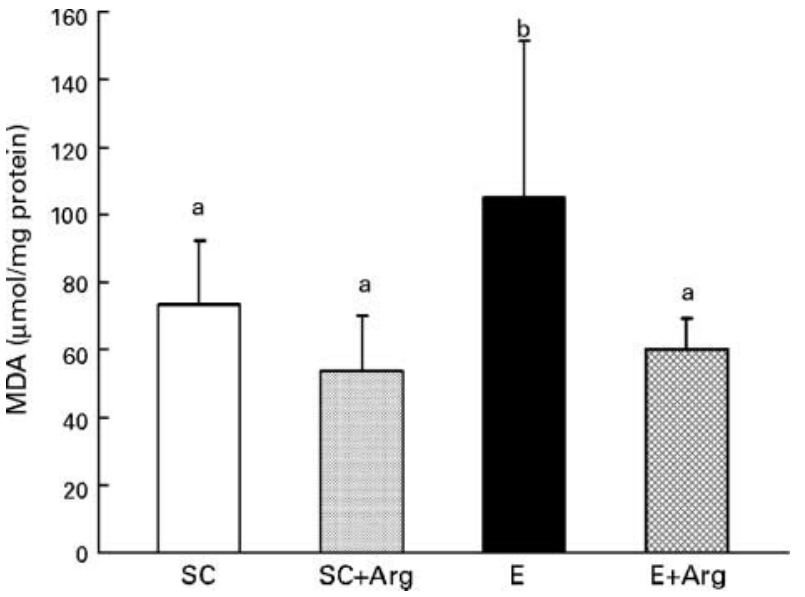

Fig. 3. Effect of L-arginine (Arg) supplementation on malondialdehyde (MDA) activity of heart tissue after exhaustive exercise (E). SC, sedentary control. Values are means for eight rats, with their standard errors represented by vertical bars. Statistical differences among the groups were determined by two-way ANOVA. ${ }^{a, b}$ Mean values with unlike letters were significantly different by Fisher's least significant difference test $(P<0.05)$. For details of diets and procedures, see p. 68 .

group $\mathrm{E}+\operatorname{Arg}$ compared with group $\mathrm{E}(P<0 \cdot 05)$. Elevations of muscle enzymes such as CK, AST, and LDH in plasma are characteristic responses to strenuous exercise and often used as indicators of muscle damage. Especially, changes in activities of AST and LDH have been used previously as indicators of myocardial damage.

\section{Antioxidant enzymes activities in the heart tissue}

Table 3 shows the antioxidant enzyme activities. The antioxidant enzyme activities of SOD and CAT in heart tissue were significantly increased by 58 and $62 \%$, respectively, in group E compared with in group SC $(P<0.05)$. In contrast, antioxidant enzyme activities of SOD, CAT, GPX, and GR in group $\mathrm{E}+\mathrm{Arg}$ were all significantly lower than those in group $\mathrm{E}(P<0 \cdot 05)$. It is possible that the higher activity of antioxidant enzymes as a result of exercise might be indicative of a compensatory measure to counteract the possible detrimental effects associated with oxidative stress.
Total and oxidised glutathione in the heart tissue

The levels of total glutathione, GSH and GSSG, and the GSH:GSSG ratio in the heart tissue are shown in Table 4. The levels of total glutathione and GSH showed no difference between groups E and SC. However, the content of GSSG in group E was significantly higher by $63 \%$ compared with that of group SC $(P<0 \cdot 05)$. However, the GSH:GSSG ratio in group E was significantly lower by $55 \%$ than that in group $\mathrm{SC}(P<0.05)$. When compared with group $\mathrm{E}$, the content of GSSG was significantly lower by $31 \%$ in group $\mathrm{E}+\mathrm{Arg}$ $(P<0 \cdot 05)$. However, the levels of total glutathione and GSH, and the GSH:GSSG ratio were all significantly increased by 55,93 and $171 \%$, respectively, in group $\mathrm{E}+$ Arg compared with those in group $\mathrm{E}(P<0 \cdot 05)$.

\section{Discussion}

Acute physical exercise increases cardiac contractility and heart rate. Strenuous exercise may be associated with a fourfold increase in blood flow through and $\mathrm{O}_{2}$ consumption by the myocardium. A number of studies have shown free radical-mediated damage during exercise-induced oxidant stress (Ji et al. 1991; Ji, 1993; Ji \& Mitchell, 1994; Sen et al. 1994; Somani et al. 1995). The present study assessed the effects of dietary L-Arg supplementation on acute strenuous exercise-induced oxidative damage of myocardium and modulations of cardiac antioxidant enzymes activities. It is the first study to examine the antioxidant potential of L-Arg using an in vivo animal exercise model.

The present results demonstrate that in exhaustive exercise with higher anaerobic components, the lactate concentration in plasma of group E (750 (SEM 60) $\mathrm{mg} / \mathrm{l})$ was significantly higher than that of group SC $(550($ SEM 40$) \mathrm{mg} / \mathrm{l})(P<0 \cdot 05)$, but not of group E $+\operatorname{Arg}(460$ (SEM 20) mg/l). This result indicates that the rats are not able to obtain a sufficient amount of $\mathrm{O}_{2}$ during running; hence, hypoxia metabolism supports a significant part of the exhaustive exercise. This situation is in accordance with some references in the literature (Radak et al. 1995; Vina et al. 2000). The production of radicals in the heart tissue after acute exhaustive exercise caused some degree of oxidative damage. The importance of this pathway is associated primarily with the consumption of ATP. An increase in the ADP:ATP ratio, followed by AMP

Table 2. Effects of L-arginine (Arg) supplementation on plasma creatinine kinase (CK), lactate dehydrogenase $(\mathrm{LDH})$, uric acid (UA), and nitrite and nitrate (NOx) levels after exhaustive exercise (E) (Mean values with their standard errors for eight rats)

\begin{tabular}{|c|c|c|c|c|c|c|c|c|}
\hline & \multicolumn{2}{|c|}{ Group SC } & \multicolumn{2}{|c|}{ Group SC + Arg } & \multicolumn{2}{|c|}{ Group E } & \multicolumn{2}{|c|}{ Group E + Arg } \\
\hline & Mean & SEM & Mean & SEM & Mean & SEM & Mean & SEM \\
\hline $\mathrm{CK}(\mathrm{U} / \mathrm{I})$ & $158^{a}$ & 7 & $231^{a}$ & 26 & $874^{\mathrm{b}}$ & 223 & $471^{a}$ & 72 \\
\hline AST $(\mathrm{U} / \mathrm{I})$ & $79^{a}$ & 3 & $90^{\mathrm{a}}$ & 6 & $143^{b}$ & 16 & $132^{b}$ & 10 \\
\hline $\mathrm{LDH}(\mathrm{U} / \mathrm{I})$ & $169^{a}$ & 18 & $373^{a, b}$ & 76 & $782^{c}$ & 146 & $521^{b}$ & 35 \\
\hline $\mathrm{UA}(\mathrm{mg} / \mathrm{l})$ & $9 \cdot 4^{\mathrm{a}}$ & 1.0 & $19 \cdot 9^{b}$ & $2 \cdot 8$ & $34 \cdot 6^{d}$ & 2.8 & $28 \cdot 0^{c}$ & $02 \cdot 1$ \\
\hline $\mathrm{NOx}(\mu \mathrm{mol} / \mathrm{l})$ & $1 \cdot 38^{a}$ & 0.14 & $1.48^{\mathrm{a}}$ & 0.20 & $2.66^{\mathrm{b}}$ & 0.18 & $2.69^{b}$ & 0.47 \\
\hline
\end{tabular}

SC, sedentary control; AST, aspartate aminotransferase.

a,b Mean values within a row with unlike superscript letters were significantly different $(P<0.05)$

For details of diets and procedures, see p. 68. 
Table 3. Effects of L-arginine (Arg) supplementation on antioxidant enzymes superoxide dismutase (SOD), catalase (CAT), glutathione peroxidase (GPX), and glutathione reductase (GR) activities of heart tissue after exhaustive exercise (E) (Mean values with their standard errors for eight rats)

\begin{tabular}{|c|c|c|c|c|c|c|c|c|}
\hline & \multicolumn{2}{|c|}{ Group SC } & \multicolumn{2}{|c|}{ Group SC + Arg } & \multicolumn{2}{|c|}{ Group E } & \multicolumn{2}{|c|}{ Group E + Arg } \\
\hline & Mean & SEM & Mean & SEM & Mean & SEM & Mean & SEM \\
\hline SOD (U/mg protein) & $15 \cdot 41^{\mathrm{b}}$ & 2.97 & $6 \cdot 40^{a}$ & $2 \cdot 10$ & $24.42^{c}$ & $4 \cdot 25$ & $3.69^{a}$ & 1.71 \\
\hline CAT (U/mg protein) & $39^{a}$ & 3 & $38^{a}$ & 4 & $63^{\mathrm{b}}$ & 3 & $45^{\mathrm{a}}$ & 3 \\
\hline GPX (U/mg protein) & $161^{a, b}$ & 6 & $150^{\mathrm{a}, \mathrm{b}}$ & 9 & $175^{\mathrm{b}}$ & 11 & $135^{\mathrm{a}}$ & 8 \\
\hline $\mathrm{GR}$ (mU/g protein) & $7 \cdot 25^{a, b}$ & $1 \cdot 14$ & $7 \cdot 60^{a, b}$ & 0.62 & $10 \cdot 01^{b}$ & $1 \cdot 32$ & $6 \cdot 67^{a}$ & 0.94 \\
\hline
\end{tabular}

SC, sedentary control.

a,b Mean values within a row with unlike superscript letters were significantly different $(P<0.05)$.

For details of diets and procedures, see p. 68.

Table 4. Effects of L-arginine (Arg) supplementation on total glutathione, GSH and GSSG concentrations, and GSH:GSSG ratio of heart tissue after exhaustive exercise $(E)$

(Mean values with their standard errors for eight rats)

\begin{tabular}{|c|c|c|c|c|c|c|c|c|}
\hline & \multicolumn{2}{|c|}{ Group SC } & \multicolumn{2}{|c|}{ Group SC + Arg } & \multicolumn{2}{|c|}{ Group E } & \multicolumn{2}{|c|}{ Group E + Arg } \\
\hline & Mean & SEM & Mean & SEM & Mean & SEM & Mean & SEM \\
\hline Total glutathione (mg/mg protein) & $0.047^{a}$ & 0.003 & $0.060^{\mathrm{b}}$ & 0.006 & $0.042^{\mathrm{a}}$ & 0.002 & $0.065^{\mathrm{b}}$ & 0.006 \\
\hline $\mathrm{GSH}$ (mg/mg protein) & $0.039^{a, b}$ & 0.003 & $0.051^{b, c}$ & 0.006 & $0.029^{a}$ & 0.002 & $0.056^{\mathrm{C}}$ & 0.005 \\
\hline GSSG (mg/mg protein) & $0.008^{a}$ & 0.001 & $0.009^{a}$ & 0.001 & $0.013^{b}$ & 0.001 & $0.009^{a}$ & 0.001 \\
\hline GSH:GSSG & $5 \cdot 33^{b}$ & 0.63 & $6 \cdot 19^{b}$ & $1 \cdot 14$ & $2 \cdot 41^{\mathrm{a}}$ & 0.36 & $6 \cdot 53^{\mathrm{b}}$ & 0.32 \\
\hline
\end{tabular}

SC, sedentary control.

a,b Mean values within a row with unlike superscript letters were significantly different $(P<0.05)$.

For details of diets and procedures, see p. 68.

and its degradation to hypoxanthine, culminates in UA increasing and $\mathrm{O}_{2}{ }^{-}$production by XO (Westing et al. 1989; Radak et al. 1995; Vina et al. 2000). Our data support the findings of the present study in which the XO activity and the UA and MDA concentrations in the heart show similar marked increases immediately following the exhaustive running. This may suggest that the XO-derived free radicals exert some deleterious effect on heart tissue. However, no such increase in $\mathrm{XO}$ was observed in the L-Arg-supplemented group in response to exercise. Numerous studies have shown NO, a biologically important molecule, to have many modulatory functions for cells and tissues. NO has been shown to be cardioprotective in ischaemia and reperfusion (Zweier et al. 1995; Au et al. 2003). Furthermore, NO may exert direct effects on cardiac myocytes (Shiono et al. 2002). The inhibition of XO by NO may be mediated through direct binding of $\mathrm{NO}$ to the enzyme $\mathrm{Fe}-\mathrm{S}$ moiety (Hassoun et al. 1995). Another study also supported this notion that NO may suppress XO activity (Fukahori et al. 1994). Hence, the protective role of NO could probably be due to its property of scavenging free radicals and inhibiting XO; this is in accordance with the present results in the $\mathrm{E}+\mathrm{Arg}$ group.

MPO has been shown to provide an index of neutrophil infiltration in tissues, and its activity has been reported to be elevated with strenuous running in several tissues of rats, including heart tissue (Belcastro et al. 1996). Our data also showed that heart MPO activity in group E was markedly increased after exhaustive exercise. Therefore, it can be concluded that XO-derived oxidants are important in the accumulation of neutrophils after exhaustive exercise. This chemotaxic potential of oxidants from $\mathrm{XO}$ is in agreement with previous investigators (Kubes et al. 1990, 1991; Nonami, 1997). However, exhaustive exercise-induced cardiac MPO activity was not significantly reduced by L-Arg supplementation.

As described earlier, lipid peroxidation, measured in the form of MDA, significantly increased in the heart tissue of the E group, also supporting the possibility of increased ROS production leading to higher rate of lipid peroxidation (Frankiewicz-Jozko et al. 1996; Venditti \& Di Meo, 1996). L-Arg supplementation, however, significantly protects heart tissue from ROS-mediated oxidative damage during exhaustive exercise.

Vina et al. (2000) have demonstrated that administration of allopurinol, an inhibitor of XO, prevents the increase of the activities of cytosolic enzymes $\mathrm{CK}$ and $\mathrm{LDH}$ in plasma after exhaustive exercise. Our data also showed that L-Arg supplementation could inhibit the elevation of XO activity and resulted in a significant decrease in plasma levels of CK and LDH in group E + Arg compared with that in group E. This finding was similar to that of a previous report (Vina et al. 2000).

Furthermore, Qian et al. (2001) and Reid (1998) have suggested that long-term strenuous exercise may stimulate the activity of NO synthase and hence increase NO synthesis, also causing a significant increase in NOx production in plasma. In the present study, the results indicate that in both the $\mathrm{E}$ and $\mathrm{E}+\mathrm{Arg}$ groups there was a significant increase in plasma NOx after exhaustive exercise compared with controls. $\mathrm{NO}$, however, is also a free radical and hence the toxicity of NO (excess production of NO) is markedly enhanced by its reaction with $\mathrm{O}_{2}^{-}$from peroxynitrite $\left(\mathrm{ONOO}^{-}\right)$, which is 
extremely cytotoxic (Beckman \& Koppenol, 1996). Numerous studies have shown that infusion of $\mathrm{ONOO}^{-}$into working rat hearts impairs cardiac contractile function by decreasing cardiac efficiency (Liu et al. 1997; Schulz et al. 1997; Yasmin et al. 1997). However, Rubbo et al. (1994) reported that NO actually inhibits peroxynitrite-induced lipid peroxidation. The data demonstrated that NO will significantly enhance lipid peroxidation only when rates of $\mathrm{NO}$ production approach or are equivalent to rates of $\mathrm{O}_{2}{ }^{-}$production by $\mathrm{XO}$. In the present study, we measured the effect of exhaustive exercise at the rate of NOx synthesis in plasma in both exercised groups. Obviously, rats in group E had significant increases in XO activity, MPO activity, MDA levels and GSSG release that will cause oxidative stress in heart tissue. It means that the enhanced production of $\mathrm{O}_{2}{ }^{-}$by $\mathrm{XO}$ may be possibly as a result of synergy between higher-level $\mathrm{NO}$ and $\mathrm{O}_{2}{ }^{-}$to form cytotoxic $\mathrm{ONOO}^{-}$after exhaustive exercise. This is in contrast with the $\mathrm{E}+\mathrm{Arg}$ group; when $\mathrm{NO}$ concentrations are increased, the protective role of NO and/or L-Arg itself may probably be due to the property of scavenging free radicals and possibly inhibiting XO as well as inflammation of neutrophils. Therefore, the present study suggests that the E + Arg group has higher levels of $\mathrm{NO}$ to inhibit $\mathrm{ONOO}^{-}$formation and it is unlikely that $\mathrm{ONOO}^{-}$may have a role in this process. The present results are in agreement with the findings of Rubbo et al. (1994); that NO alone does not induce lipid peroxidation. Thus, we conclude that NO can exacerbate oxidant injury via the production of the potent oxidant $\mathrm{ONOO}^{-}$or exert a protective role via scavenging $\mathrm{O}_{2}{ }^{-}$by termination of free radical-dependent chain-propagation reactions by diverse initiating species.

It is well known that SOD, CAT, GPX and GR are regarded as the first line of the antioxidant enzyme system against ROS generated during exhaustive exercise. The present study showed that these enzymes are increased as a compensatory mechanism in response to the increase of oxidative stress due to exhaustive exercise. It means that the increased $\mathrm{XO}$ observed in the present study denotes the increased generation of $\mathrm{O}_{2}{ }^{-}$, which will have triggered the activation of SOD by dismutating $\mathrm{O}_{2}{ }^{-}$to $\mathrm{H}_{2} \mathrm{O}_{2}$. This result is supported by previous studies (Ji, 1993; Somani et al. 1995; Leeuwenburgh et al. 1996). The increased CAT activity levels in heart (162\%) observed in the present study were also presented in Somani et al. (1995), who observed CAT activity increase by $358 \%$ in the heart of rats subjected to acute strenuous exercise. Our data show that SOD and CAT activities were significantly lower or were not different in the E + Arg group compared with the control groups. These results indicate that L-Arg supplementation has beneficial effects on attenuating the oxidative stress induced by exhaustive exercise. The increased activity of GPX in heart after acute strenuous exercise has been reported in a previous study; GPX converts $\mathrm{H}_{2} \mathrm{O}_{2}$ to water and $\mathrm{O}_{2}$ to cope with abrupt exercise-induced oxidant stress (Somani et al. 1995). In addition, we found significantly increased heart GR activity in the E group. However, it is different from the results of a few reports showing no change (Ji, 1993; Leeuwenburgh et al. 1996). It may be possible that myocardium shows a marked GR adaptation to GSH depletion and increased GSSG levels in the present study. However, growing evidence (Ji, 1993; Somani et al. 1995; Leeuwenburgh et al. 1996) suggests that some antioxidant enzymes can be increased in myocardium actively involved in exhaustive exercise. The results of the present study indicate that myocardium of the E group may be more susceptible to oxidative stress than that of the SC group. These disparate results may be due to differences in tissues or organs, exercise intensity, duration and mode of exercise.

GSH is a major non-enzymic antioxidant and has been reported to play an important role in protecting the myocardium from ischaemia and reperfusion-induced oxidative damage (Ji, 2002). Previous studies have shown a decrease in the myocardial GSH of rats after a vigorous swimming exercise and exercise running (Kihlstrom et al. 1989; Seward et al. 1995; Leichtweis et al. 1997). Also, the GSH:GSSG ratio decreases in the myocardium of exhausted rats (Sen et al. 1994). Subsequent studies also reported that levels of total glutathione fell in exhaustive-exercise rats (Duarte et al. 1993). In the present study, we found that GSSG was significantly increased and that the GSH:GSSG ratio was significantly decreased in the $\mathrm{E}$ group, but GSH did not reach statistical significance $(P=0 \cdot 0687)$. Also, total glutathione did not change significantly in the E group compared with the SC group. However, L-Arg supplementation significantly increased total glutathione and GSH in both the $\mathrm{SC}+\mathrm{Arg}$ and $\mathrm{E}+\mathrm{Arg}$ groups. As a result of the protective effect of L-Arg, GSSG level significantly decreased in comparison with the E group. It means that healthy non-stressed cells maintain notably a high intracellular GSH:GSSG ratio to ensure the availability of GSH, and thereby promote active reduction of $\mathrm{H}_{2} \mathrm{O}_{2}$ through the $\mathrm{GSH}$ redox cycle. The effects of L-Arg supplementation in exhaustively exercised animals on enzymic and non-enzymic antioxidant systems cannot be clearly explained at present. They are probably related to the following two mechanisms. First, L-Arg serves as a precursor of the synthesis of NO that may have an indirect antioxidant role to scavenge $\mathrm{O}_{2}{ }^{-}$and inhibit $\mathrm{XO}$ activity from exercise-induced stress (Pabla et al. 1996). The present results suggest that the protection by L-Arg may, through the generation of NO, reduce ROS formation via the inhibition of XO activity, to prevent cellular damage; but, in the presence of NO synthase inhibitor L-NAME, this protection is abolished (Wascher et al. 1997). Second, L-Arg has some protective roles against ROS attack by its direct chemical property interaction with $\mathrm{O}_{2}{ }^{-}$(Wascher et al. 1997; Lass et al. 2002). Hence, it may be possible to maintain normal enzymic and non-enzymic antioxidant systems of the redox cycle after exhaustive exercise. By contrast, non-Arg supplementation of rats significantly increases these antioxidant enzymes and decreases the GSH:GSSG ratio, possibly as a compensatory mechanism to cope with the enhanced production of ROS during exhaustive exercise.

In conclusion, the present results support the mechanism that the increase of XO and MPO activities is the main pathway involved in the production of free radicals during exhaustive exercise. Our data also indicate that the administration of L-Arg could prevent exhaustive exercise-induced production of lipid peroxide levels, elevation of XO activity, and imbalance of antioxidant enzymes activities. Our findings may have important implications in the development of therapeutic strategies aimed at manipulating L-Arg supplementation for NO production and/or L-Arg itself in exercise-induced oxidative stress. 


\section{Acknowledgements}

This project was supported by the Shin Kong $\mathrm{Wu} \mathrm{Ho}-\mathrm{Su}$ Memorial Hospital of Taiwan, SKH-FJU-92-13.

\section{References}

Ashton T, Rowlands CC, Jones E, Young IS, Jackson SK, Davies B \& Peters JR (1998) Electron spin resonance spectroscopic detection of oxygen-centred radicals in human serum following exhaustive exercise. Eur J Appl Physiol Occup Physiol 77, 498-502.

Au A, Louch WE, Ferrier GR \& Howlett SE (2003) L-Arginine ameliorates effects of ischemia and reperfusion in isolated cardiac myocytes. Eur J Pharmacol 476, 45-54.

Beckman JS \& Koppenol WH (1996) Nitric oxide, superoxide, and peroxynitrite: the good, the bad and ugly. Am J Physiol 271, C1424-C1437.

Beers RF Jr \& Sizer IW (1952) A spectrophotometric method for measuring the breakdown of hydrogen peroxide by catalase. $J$ Biol Chem 195, 133-140.

Belcastro AN, Arthur GD, Albisser TA \& Raj DA (1996) Heart, liver, and skeletal muscle myeloperoxidase activity during exercise. $J$ Appl Physiol 80, 1331-1335.

Brooks GA \& White TP (1978) Determination of metabolic and heart rate responses of rats to treadmill exercise. J Appl Physiol 45, 1009-1015.

de Oliveira SL, Diniz DB \& Amaya-Farfan J (2003) Carbohydrateenergy restriction may protect the rat brain against oxidative damage and improve physical performance. Br J Nutr 89, 89-96.

Duarte JA, Appell HJ, Carvalho F, Bastos ML \& Soares JM (1993) Endothelium-derived oxidative stress may contribute to exerciseinduced muscle damage. Int J Sports Med 14, 440-443.

Fielding RA, Manfredi T, Ding W, Fiatarone MA, Evans WJ \& Cannon JG (1993) Acute phase response in exercise. III. Neutrophil and IL-1 beta accumulation in skeletal muscle. Am J Physiol 265, R166-R172.

Frankiewicz-Jozko A, Faff J \& Sieradzan-Gabelska B (1996) Changes in concentrations of tissue free radical marker and serum creatine kinase during the post-exercise period in rats. Eur J Appl Physiol 74, 470-474.

Fukahori M, Ichimori K, Ishida H, Nakagawa H \& Okino H (1994) Nitric oxide reversibly suppresses xanthine oxidase activity. Free Radic Res 21, 203-212.

Green LC, Wagner DA, Glogowski J, Skipper PL, Wishnok JS \& Tannenbaum SR (1982) Analysis of nitrate, nitrite and [15N]nitrate in biological fluids. Anal Biochem 126, 131-138.

Griffith OW (1980) Determination of glutathione and glutathione disulfide using glutathione reductase and 2-vinylpyridine. Anal Biochem 106, 207-212.

Hassoun PM, Yu FS, Zulueta JJ, White AC \& Lanzillo JJ (1995) Effect of nitric oxide and cell redox status on the regulation of endothelial cell xanthine dehydrogenase. Am $J$ Physiol 268, L809-L817.

Hellsten Y, Frandsen U, Orthenblad N, Sjodin B \& Richter EA (1997) Xanthine oxidase in human skeletal muscle following eccentric exercise: a role in inflammation. $J$ Physiol 498, 239-248.

Ji LL (1993) Antioxidant enzyme responds to exercise and aging. Med Sci Sports Exerc 25, 225-231.

Ji LL (1999) Antioxidants and oxidative stress in exercise. Proc Soc Exp Biol Med 222, 283-292.

Ji LL (2002) Exercise-induced modulation of antioxidant defense. Ann N Y Acad Sci 959, 82-92.

Ji LL, Dillon D \& Wu E (1991) Myocardial aging: antioxidant enzyme systems and related biochemical properties. Am J Physiol 261, R386-R392.
Ji LL \& Mitchell EW (1994) Effects of Adriamycin on heart mitochondrial function in rested and exercised rats. Biochem Pharmacol 47, 877-885.

Judge AR \& Dodd SL (2004) Xanthine oxidase and activated neutrophils cause oxidative damage to skeletal muscle after contractile claudication. Am J Physiol 286, H252-H256.

Kihlstrom M, Ojala J \& Salminen A (1989) Decreased level of cardiac antioxidants in endurance-trained rats. Acta Physiol Scand 135, 549-554.

Kubes P, Suzuki M \& Granger DN (1990) Modulation of PAFinduced leukocyte adherence and increased microvascular permeability. Am J Physiol 259, G859-G864.

Kubes P, Suzuki M \& Granger DN (1991) Nitric oxide: an endogenous modulator of leukocyte adhesion. PNAS 88, 4651-4655.

Kumar CT, Reddy VK, Prasad M, Thyagaraju K \& Reddanna P (1992) Dietary supplementation of vitamin E protects heart tissue from exercise-induced oxidant stress. Mol Cell Biochem 111, 109-115.

Lass A, Suessenbacher A, Wolkart G, Mayer B \& Brunner F (2002) Functional and analytical evidence for scavenging of oxygen radicals by L-arginine. Mol Pharmacol 61, 1081-1088.

Leeuwenburgh C, Leichtweis S, Hollander J, Fiebig R, Groe M \& Ji LL (1996) Effect of acute exercise on glutathione deficient heart. Mol Cell Biochem 156, 17-24.

Leichtweis SB, Leeuwenburgh C, Parmelee DJ, Fiebig R \& Ji LL (1997) Rigorous swim training impairs mitochondrial function in post-ischaemic rat heart. Acta Physiol Scand 160, 139-148.

Lewis B \& Langkamp-Henken B (2000) Arginine enhances in vivo immune responses in young, adult and aged mice. J Nutr 130, $1827-1830$.

Liu P, Hock CE, Nagele R \& Wong PY (1997) Formation of nitric oxide, superoxide, and peroxynitrite in myocardial ischemia-reperfusion injury in rats. Am J Physiol 272, H2327-H2336.

Lowry OH, Rosebrough NJ, Lewis Farr A \& Randall RJ (1951) Protein measurement with the Folin phenol reagent. J Biol Chem 193, 265-275.

McCord JM (1985) Oxygen-derived free radicals in postischemic tissue injury. $N$ Engl J Med 312, 159-163.

Mullane KM, Kraemer R \& Smith B (1985) Myeloperoxidase activity as a quantitative assessment of neutrophil infiltration into ischemic myocardium. J Pharmacol Methods 14, 157-167.

Nonami Y (1997) The role of nitric oxide in cardiac ischemia-reperfusion injury. Jpn Circ J 61, 119-132.

Pabla R, Buda AJ, Flynn DM, Blesse SA, Shin AM, Curtis MJ \& Lefer DJ (1996) Nitric oxide attenuates neutrophil-mediated myocardial contractile dysfunction after ischemia and reperfusion. Circ Res 78, 65-72.

Qian ZM, Xiao DS, Ke Y \& Liao QK (2001) Increased nitric oxide is one of the causes of changes of iron metabolism in strenuously exercised rats. Am J Physiol 280, R739-R743.

Radak Z, Asano K, Inoue M, Kizaki T, Oh-Ishi S, Suzuki K, Taniguchi N \& Ohno H (1995) Superoxide dismutase derivative reduces oxidative damage in skeletal muscle of rats during exhaustive exercise. J Appl Physiol 79, 129-135.

Radak Z, Nakamura A, Nakamoto H, Asano K, Ohno H \& Goto S (1998) A period of anaerobic exercise increases the accumulation of reactive carbonyl derivatives in the lungs of rats. Pflugers Arch 435, 439-441.

Reeves PG, Nielsen FH \& Fahey GC Jr (1993) AIN-93 purified diets for laboratory rodents: final report of the American Institute of Nutrition ad hoc writing committee on the reformulation of the AIN-76A rodent diet. J Nutr 123, 1939-1951.

Reid MB (1998) Role of nitric oxide in skeletal muscle: synthesis, distribution and functional importance. Acta Physiol Scand 162, 401-409.

Rubbo H, Radi R, Trujillo M, Telleri R, Kalyanaraman B, Barnes S, Kirk M \& Freeman BA (1994) Nitric oxide regulation of 
superoxide and peroxylnitrite-dependent lipid peroxidation. Formation of novel nitrogen-containing oxidized lipid derivatives. $J$ Biol Chem 269, 26066-26075.

Schaefer A, Piquard F, Geny B, Doutreleau S, Lampert E, Mettauer B \& Lonsdorfer J (2002) L-Arginine reduces exercise-induced increase in plasma lactate and ammonia. Int J Sports Med 23, 403-407.

Schierwagen C, Bylund-Fellenius AC \& Lundberg C (1990) Improved method for quantification of tissue PMN accumulation measured by myeloperoxidase activity. J Pharmacol Methods 23, $179-186$.

Schmidt HH, Warner TD, Nakane M, Forstermann U \& Murad F (1992) Regulation and subcellular location of nitrogen oxide synthases in RAW264.7 macrophages. Mol Pharmacol 41, 615-624.

Schulz R, Dodge KL, Lopaschuk GD \& Clanachan AS (1997) Peroxynitrite impairs cardiac contractile function by decreasing cardiac efficiency. Am J Physiol 272, H1212-H1219.

Sen CK, Atalay M \& Hanninen O (1994) Exercise-induced oxidative stress: glutathione supplementation and deficiency. J Appl Physiol 77, 2177-2187.

Seward SW, Seiler KS \& Starnes JW (1995) Intrinsic myocardial function and oxidative stress after exhaustive exercise. J Appl Physiol 79, 251-255.

Shiono N, Rao V, Weisel RD, Kawasaki M, Li RK, Mickle DAG, Fedak PWM, Tumiati LC, Ko L \& Verma S (2002) L-Arginine protects human heart cells from low-volume anoxia and reoxygenation. Am J Physiol 282, H805-H815.

Somani SM, Frank S \& Rybak LP (1995) Responses of antioxidant system to acute and trained exercise in rat heart subcellular fractions. Pharmacol Biochem Behav 51, 627-634.

Tietze F (1969) Enzymic method for quantitative determination of nanogram amounts of total and oxidized glutathione: applications to mammalian blood and other tissues. Anal Biochem 27, 502-522.
Tiidus PM (1998) Radical species in inflammation and overtraining. Can J Physiol Pharmacol 76, 533-538.

Venditti P \& Di Meo S (1996) Antioxidants, tissue damage, and endurance in trained and untrained young male rats. Arch Biochem Biophys 331, 63-68.

Vina J, Gimeno A, Sastre J, Desco C, Asensi M, Pallardo FV, Cuesta A, Ferrero JA, Terada LS \& Repine JE (2000) Mechanism of free radical production in exhaustive exercise in humans and rats; role of xanthine oxidase and protection by allopurinol. IUBMB Life $\mathbf{4 9}$, $539-544$.

Wang BY, Singer AH, Tsao PS, Drexler H, Kosek J \& Cooke JP (1994) Dietary arginine prevents atherogenesis in the coronary artery of the hypercholesterolemic rabbit. $\mathrm{J} \mathrm{Am} \mathrm{Coll} \mathrm{Cardiol} \mathbf{2 3}$, $452-458$.

Wascher TC, Posch K, Wallner S, Hermetter A, Kostner GM \& Graier WF (1997) Vascular effects of L-arginine: anything beyond a substrate for the NO-synthase? Biochem Biophys Res Commun 234, 35-38.

Westerfeld WW, Richert DA \& Higgins ES (1959) Further studies with xanthine oxidase inhibitors. J Biol Chem 234, 1897-1900.

Westing YH, Ekblom B \& Sjodin B (1989) The metabolic relation between hypoxanthine and uric acid in man following maximal short-distance running. Acta Physiol Scand 137, 341-345.

Wu G \& Morris SM Jr (1998) Arginine metabolism: nitric oxide and beyond. Biochem J 336, 1-17.

Xiao DS, Jiang L, Che LL \& Lu L (2003) Nitric oxide and iron metabolism in exercised rat with L-arginine supplementation. Mol Cell Biochem 252, 65-72.

Yasmin W, Strynadka KD \& Schulz R (1997) Generation of peroxynitrite contributes to ischemia-reperfusion injury in isolated rat hearts. Cardiovasc Res 33, 422-432.

Zweier JL, Wang P, Samouilov A \& Kuppusamy P (1995) Enzymeindependent formation of nitric oxide in biological tissues. Nat Med 1, 804-809. 